\title{
Ethane Oxydehydrogenation over Supported Vanadium Oxides
}

Chih-Yu Kao, Kuang-Tse Huang, and Ben-Zu Wan

Ind. Eng. Chem. Res., 1994, 33 (9), 2066-2072 • DOI: 10.1021/ie00033a007

Downloaded from http://pubs.acs.org on November 26, 2008

\section{More About This Article}

The permalink http://dx.doi.org/10.1021/ie00033a007 provides access to:

- $\quad$ Links to articles and content related to this article

- Copyright permission to reproduce figures and/or text from this article

\section{ACS Publications}




\title{
Ethane Oxydehydrogenation over Supported Vanadium Oxides
}

\author{
Chih-Yu Kao, Kuang-Tse Huang, and Ben-Zu Wan* \\ Department of Chemical Engineering, National Taiwan University, Taipei, Taiwan, R.O.C.
}

Ethane oxydehydrogenation to produce ethylene was studied over vanadium oxides supported on either silica gel, HZSM-5, silicalite, or $\mathrm{AlPO}_{4}-5$. Characterization of the catalysts was carried out by X-ray photoelectron spectroscopy for the vanadium binding energy, temperature-programmed desorption of ammonia for the number of acidic sites on the supports, and redox titration for the number of chemisorption sites on vanadium oxides. The results of kinetic studies showed that the ethane oxydehydrogenation rates over vanadium oxide were enhanced by the presence of acidic sites on the supports. The rate equations thus derived suggested that the reduction of vanadium oxide sites by adsorbed ethane was the rate-determining step. It is likely that the support acidity can either promote the vanadium oxide reduction activity or increase the equilibrium constant of ethane adsorption on the catalyst.

\section{Introduction}

The transformation of ethane into ethylene is important in the petrochemical industry. In the conventional endothermic dehydrogenation process, the conversion is limited by the reaction thermodynamic equilibrium; however, this limitation can be eliminated by the addition of oxygen so that the reaction becomes an oxydehydrogenation process and alters to be exothermic. Its rate is enhanced sharply along with the production of water. Among the catalysts studied for ethane oxydehydrogenation, vanadium oxide has been reported to be one of the more effective metal oxide catalysts. Thoresteinson et al. (1978) and Burch and Swarnaker (1991) examined mixed oxide catalysts containing vanadium, molybdenum, and niobium. It was found that the oxydehydrogenation activity was correlated with the reducibility of the catalysts. On the other aspect, vanadium oxide supported on silica was studied by several authors (Erdöhelyi and Solymosi, 1988, 1990, 1991; Oyama and Somorjai, 1990; Oyama et al., 1990; Oyama, 1991; Le Bars et al., 1992a,b). Oyama et al. $(1990,1991)$ reported that the production of ethylene and acetaldehyde from ethane followed a structureinsensitive reaction path, while the production of $\mathrm{CO}_{x}$ was structure-sensitive. Furthermore, water in the reaction system was found to have a strong influence on the product selectivity. Recently, Le Bars et al. (1992a,b) investigated the effect of acidity of vanadium oxide supported on silica in ethane oxydehydrogenation. They found that the catalytic activity increased with the vanadium content and acidity, but the selectivity of ethylene was favored with low vanadium loading. In a separate study, Erdöhelyi and Solymosi (1988) found that when alkali metal (i.e., potassium) was added as promoter, the formation of ethylene was suppressed and the selectivity of acetaldehyde was increased.

In the present work, vanadium oxide was supported on silicalite, $\mathrm{HZSM}-5$, and $\mathrm{AlPO}_{4}-5$ of microporous structures. Ethane oxydehydrogenation was studied over these catalysts, and the results were compared with those from vanadium oxide supported on silica. The reason for using these molecular-sieve type supports was their good catalytic activities in the oligomerization of ethylene to larger hydrocarbons and aromatics. Recently, Fujimoto et al. (1989) reported that oxygen could reduce the surface hydrogen concentration and enhance the formation of aromatics during lower paraffin conversion over HZSM-

* To whom all correspondence should be addressed.
5. Therefore, vanadium oxide supported on these molecular sieves may be applied as oxydehydrogenation catalysts for converting ethane to more valuable chemicals besides ethylene. However, in order to investigate the support effect on the primary reaction (ethane oxydehydrogenation to ethylene), the conversion of ethane was maintained at a low level in this reserach. The catalysts were characterized with X-ray photoelectron spectroscopy for binding energies of vanadium, temperature-programmed desorption of ammonia for support acidities, and oxygen chemisorption measurement for the dispersions of vanadium oxide on the supports. The reaction kinetics were studied in order to elucidate the effect of supports and the possible reaction paths over these catalysts.

\section{Experimental Section}

Catalyst Preparation. Silicalite, HZSM-5, and Al$\mathrm{PO}_{4}-5$ were prepared following the hydrothermal crystallization method reported in the literature (Wan and Yang, 1990; Wan et al., 1991; Wan and Huang, 1991). Silica was purchased from Yakuri Chemicals. $\mathrm{V}_{2} \mathrm{O}_{5}$ was from Nakarai Chemicals, Ltd. Vanadium solution was prepared by dissolving $2.7 \mathrm{~g}$ of ammonium metavanadate and $7.5 \mathrm{~g}$ of tartaric acid in $30 \mathrm{~mL}$ of water, followed by refluxing at $110^{\circ} \mathrm{C}$ for $2 \mathrm{~h}$. The incipient wetness technique was used for the impregnation of vanadium onto silica, silicalite, HZSM-5, and $\mathrm{AlPO}_{4}-5$. The samples were then dried at room temperature and calcined at $500^{\circ} \mathrm{C}$ overnight. These as-prepared catalysts were designated as IV/silica, IV/ silicalite, IV/ZSM-5, and IV/AlPO ${ }_{4}-5$.

In another preparation, the vanadium solution (the same as those previously used for the impregnation) was added into the aluminophosphate precursor gel. The mole ratios of the chemical components in the gel were $\mathrm{Al}_{2} \mathrm{O}_{3}: \mathrm{H}_{3} \mathrm{PO}_{4}$ : $\mathrm{V}: \mathrm{Et}_{3} \mathrm{~N}: \mathrm{H}_{2} \mathrm{O}=0.1: 0.2: 0.0077: 0.15: 3.5$. The same crystallization procedures as those for $\mathrm{AlPO}_{4}-5$ were applied (Wan et al., 1991; Wan and Huang, 1991). The resultant crystals were washed thoroughly with deionized water and dried at room temperature. This as-synthesized sample was designated as VAPO-5-101. It was subsequently calcined at $600{ }^{\circ} \mathrm{C}$ for $6 \mathrm{~h}$, ion-exchanged with $1 \mathrm{M}$ ammonium nitrate solution three times at room temperature, followed by washing, drying, and calcination again. This resultant sample was designated as HVAPO-5-101.

XRD Measurements and Chemical Analysis. The $\mathrm{X}$-ray diffraction (XRD) patterns were obtained with a Philips diffractometer (Model PW1729) using the Ni 
filtered $\mathrm{CuK} \alpha$ radiation. The BET surface area was measured with a Micromeritic Accusorb 2100D unit. The elemental content was determined by an atomic absorption unit (GBC 906).

XPS Measurements. A Perkin-Elmer (Model 548) $\mathrm{X}$-ray photoelectron spectrometer, using $\mathrm{Mg} \mathrm{K} \alpha$ monochromatic X-ray and equipped with a charge-compensating electron gun, was used for surface analysis. Prior to the measurement, the sample of powder form was pressed (5 $\times 10^{7} \mathrm{~N} / \mathrm{m}^{2}$ ) into a pellet and evacuated at $200^{\circ} \mathrm{C}$ for 2 $h$ in order to remove adsorbed water. The spectra were taken at room temperature. The binding energies (BE) were determined by referring to the $\mathrm{C} 1 \mathrm{~s}$ line at $284.6 \mathrm{eV}$.

Acidity and Number of Acidity Site Measurements. The acidity of the supports was measured by temperatureprogrammed desorption (TPD) of ammonia with a DuPont microbalance (Model 9900). Prior to ammonia adsorption, samples were preheated to $550^{\circ} \mathrm{C}$ under a $60 \mathrm{~mL} / \mathrm{min}$ nitrogen flow. Ammonia adsorption was made at room temperature for $30 \mathrm{~min}$. After purging away ammonia in the bulk of the reactor under $30 \mathrm{~mL} / \mathrm{min}$ nitrogen flow at $30^{\circ} \mathrm{C}$, the TPD of ammonia was carried out at heating rate of $10^{\circ} \mathrm{C} / \mathrm{min}$ until $500^{\circ} \mathrm{C}$.

Number of Vanadium Active Site Measurements. The number of surface chemisorption sites of vanadium oxides was measured following the method developed by Oyama et al. (1989). The catalysts were reduced by hydrogen at $367^{\circ} \mathrm{C}$ and then titrated with oxygen at the same temperature. On the basis of the amount of oxygen consumed, the number of active sites and the dispersion of vanadium were calculated. The dispersion of vanadium is defined as the moles of oxygen atom chemisorbed divided by moles of vanadium loaded on the catalyst.

Ethane Oxydehydrogenation Activity Measurements. Ethane oxydehydrogenation was carried out in a plug-flow type system equipped with a quartz reactor (9$\mathrm{mm}$ o.d.). The flow rates of ethane, oxygen, and nitrogen were controlled by Brooks mass flow controllers. The hydrocarbon and carbon dioxide products were analyzed by an on-line gas chromatograph (GC) (China Chromatography, 8700T GC) equipped with a thermal conductivity detector (TCD). A 6-ft Porapak S column (1/8-in. o.d., stainless steel) was used for separation, and hydrogen was the carrier gas. Carbon monoxide and oxygen were separated by a 6-ft molecular sieve column (1/8-in. o.d. stainless steel) in another GC (H.P. Chromatography, Model 5790), also with a TCD and hydrogen carrier. The selecivity was calculated on a carbon basis and was defined as (mol of the given hydrocarbon $\times$ no. of carbon atoms in the molecular formula)/(mol of ethane consumed $\times 2$ ).

\section{Results and Discussion}

Characterization of Physicochemical Properties. The XRD patterns showed that the synthesized HZSM-5, silicalite, and $\mathrm{AlPO}_{4}-5$ had the same crystal structures as those described in the literature (Wan and Huang, 1991). Moreover, the synthesized VAPO-5-101 catalyst possessed an XRD pattern similar to that of $\mathrm{AlPO}_{4}-5$. The green color of this sample suggested that vanadium within the crystals had an oxidation state of IV or III. After calcination at $600^{\circ} \mathrm{C}$ for $6 \mathrm{~h}$ under air, the color changed to yellow, indicating that vanadium(III or IV) was oxidized to vanadium(V). The XRD pattern of the calcined VAPO5-101 sample showed that most of its crystal structure was retained with only a small portion of dense phase being formed, which gave diffraction peaks at $2 \theta$ of $19-23$. Similar results were also reported by Rigutto and Bekkum (1993), in which different procedures for the synthesis of VAPO-5 were used, but vanadium (IV) in the as-
Table 1. Surface Area, Binding Energy, and Vanadium Dispersion of Supported Vanadium Oxides

\begin{tabular}{|c|c|c|c|c|c|}
\hline catalyst & $\begin{array}{c}\text { wt \% } \\
V\end{array}$ & $\begin{array}{l}\mathrm{SA},{ }^{a} \\
\mathrm{~m}^{2} / \mathrm{g}\end{array}$ & $\begin{array}{c}\mathrm{BE}^{b} \\
\mathrm{eV}\end{array}$ & $\operatorname{disp}^{c}$ & $\begin{array}{c}C_{\mathrm{t}},{ }^{d} 10^{-5} \\
\mathrm{~mol} \text { of } \mathrm{V} / \mathrm{g}\end{array}$ \\
\hline $\begin{array}{l}\text { HVAPO-5-101 } \\
\text { IV/AlPO } 4-5 \\
\text { IV/silica } \\
\text { IV/silicalite } \\
\text { IV/ZSM-5 } \\
\mathrm{V}_{2} \mathrm{O}_{5}\end{array}$ & $\begin{array}{l}0.64 \\
0.89 \\
0.89 \\
0.94 \\
0.78\end{array}$ & $\begin{array}{r}159 \\
90 \\
402 \\
408 \\
395\end{array}$ & $\begin{array}{l}520.6 \\
521.0 \\
519.6 \\
519.6 \\
517.4\end{array}$ & $\begin{array}{l}0.37 \\
0.47 \\
0.37 \\
0.83 \\
0.64\end{array}$ & $\begin{array}{c}4.65 \\
8.21 \\
6.46 \\
15.3 \\
9.80\end{array}$ \\
\hline
\end{tabular}

${ }^{a}$ BET surface area. ${ }^{b}$ Binding energy of $\mathrm{V} 2 \mathrm{p}_{3 / 2}$ referenced to $\mathrm{C}$ $1 \mathrm{~s}$ of $284.6 \mathrm{eV}$. ${ }^{\circ}$ Dispersion of vanadium oxide. $d$ Total number of active sites.

synthesized sample also changed to +5 oxidation state after calcination. On the other hand, the impregnated samples had a pale blue color on the as-prepared samples, indicating that vanadium possessed an oxidation state of +4. After calcination at $500^{\circ} \mathrm{C}$ under air overnight, the color transfered to yellow, demonstrating that vanadium(V) oxide was probably formed on the support surfaces. In summary, the vanadium in all the calcined samples prepared by either impregnation or coprecipitation (VAPO5) was vanadium(V) oxide.

Table 1 lists the analytic data of the vanadium loading, BET surface area, the binding energy (BE) of $V 2 p_{3 / 2}$, and the $\mathrm{V}_{2} \mathrm{O}_{5}$ dispersion. XPS results show that all the $\mathrm{BE}$ of vanadium on the supports have values larger than that of $\mathrm{V}_{2} \mathrm{O}_{5}$. This increase in the binding energies of vanadium(V) is likely due to the metal-support interactions. A similar electron-withdrawing phenomenon for $\mathrm{V}_{2} \mathrm{O}_{5}$ supported on silica was also reported in the literature (Fierro et al., 1983; Gil-Llambi'as et al., 1985; Nag and Massoth, 1990). Furthermore, it was found that the binding energies of $\mathrm{V} 2 \mathrm{p}_{3 / 2}$ for HVAPO-5-101 and IV/AlPO 4 , both of aluminophosphate supports, were larger than those for IV/ZSM-5 and IV/silicalite of mainly silicon oxide supports. Since electron negativities of the three elements in the framework of molecular sieves decrease in the order of $\mathrm{P}(2.06)>\mathrm{Si}(1.74)>\mathrm{Al}(1.47)$ (Cotton and Wilkinson, 1972), this suggests that vanadium in HVAPO-5-101 and IV/AlPO $4^{-5}$ is located near phosphorus rather than aluminum of the aluminophosphate surface. The same conclusion has been drawn by Rigutto and Bekkum (1993) from their solid state NMR study of VAPO-5.

The results of vanadium dispersion measured by oxygen titration are also shown in Table 1. This demonstrates that the vanadium dispersions on HVAPO-5-101, IV/ $\mathrm{AlPO}_{4}-5$, and IV/silica are much lower than those on IV/ ZSM-5 and IV/silicalite. This implies that vanadium oxide on aluminophosphate surface is more easily coagulated during calcination than that on silicalite and HZSM-5. However, vanadium of low dispersion supported on silica has been reported by Le Bars et al. (1992a). Since silica, silicalite, and HZSM-5 all contain mainly silicon dioxide, the composition of the supports does not seem to be the major factor in determining the dispersion of vanadium. Instead, the crystal structure of HZSM-5 and silicalite might play an important role for the high dispersion.

Acidity Measurement. Table 2 tabulates the results of TPD of ammonia in two temperature ranges. Only IV/ ZSM-5 possessed a desorption band between 250 and 500 ${ }^{\circ} \mathrm{C}$ (maximum temperature at $406^{\circ} \mathrm{C}$ ), which corresponded to the Brönsted acidity sites in the framework (Wan and Yang, 1990; Lok et al., 1986). From elemental analysis, the aluminum loading in IV/ZSM-5 was $0.58 \mathrm{mmol} / \mathrm{g}$. Therefore, the adsorption of $0.42 \mathrm{mmol}$ of ammonia/g around $406{ }^{\circ} \mathrm{C}$ indicates that $72 \%$ of the aluminum contributes to the Brönsted acidity sites for chemisorption of ammonia. The remaining $28 \%$ aluminum might only occlude in the HZSM-5 cavities. 
Table 2. Temperature-Programmed Desorption of Ammonia over Supported Vanadium Oxide Catalysts

\begin{tabular}{|c|c|c|}
\hline \multirow[b]{2}{*}{ catalyst } & \multicolumn{2}{|c|}{ accumulated desorbed $\mathrm{NH}_{3} \mathrm{mmol} / \mathrm{g}\left(\mu \mathrm{mol} / \mathrm{m}^{2}\right)$} \\
\hline & $T^{a}<250^{\circ} \mathrm{C}$ & $250^{\circ} \mathrm{C}<T<500^{\circ} \mathrm{C}$ \\
\hline HVAPO-5-101 & $7.48(49.3)$ & 0.00 \\
\hline IV $/ \mathrm{AlPO}_{4}-5$ & $1.76(19.6)$ & 0.00 \\
\hline IV/silica & $2.40(5.97)$ & 0.00 \\
\hline IV/silicalite & $2.32(5.69)$ & 0.00 \\
\hline IV/ZSM-5b & $2.56(6.48)$ & $0.42^{c}(1.06)$ \\
\hline
\end{tabular}

${ }^{a}$ Desorption temperature. ${ }^{b} \mathrm{Si} / \mathrm{Al}$ ratio $=27 / 1$, $^{c}$ Temperature of desorption band $=406^{\circ} \mathrm{C}$.

Table 3. Ethane Oxydehydrogenation over Supported Vanadium Oxide and HZSM-5"

\begin{tabular}{|c|c|c|c|c|c|}
\hline \multirow[b]{2}{*}{ catalyst } & \multirow[b]{2}{*}{ conv, $b \%$} & \multicolumn{3}{|c|}{ selectivity, \% } & \multirow[b]{2}{*}{$T,{ }^{\circ} \mathrm{C}$} \\
\hline & & $\mathrm{C}_{2} \mathrm{H}_{4}$ & $\mathrm{CO}_{2}$ & $\mathrm{CO}$ & \\
\hline \multirow[t]{4}{*}{ HVAPO-5-101 } & 0.69 & 49.0 & 14.2 & 36.6 & 400 \\
\hline & 1.34 & 45.3 & 14.0 & 40.6 & 425 \\
\hline & 2.35 & 44.8 & 14.7 & 40.5 & 450 \\
\hline & 4.56 & 42.7 & 13.7 & 43.5 & 475 \\
\hline \multirow[t]{3}{*}{ IV/AlPO $4-5$} & 0.31 & 58.4 & 10.9 & 29.6 & 400 \\
\hline & 0.52 & 50.6 & 9.4 & 39.3 & 425 \\
\hline & 0.93 & 48.6 & 8.6 & 42.4 & 450 \\
\hline \multirow[t]{4}{*}{ IV/silica } & 0.10 & 92.1 & 3.2 & 0.0 & 400 \\
\hline & 0.19 & 71.9 & 10.7 & 13.7 & 425 \\
\hline & 0.36 & 62.1 & 14.5 & 20.4 & 450 \\
\hline & 0.92 & 53.8 & 16.9 & 27.4 & 475 \\
\hline \multirow{4}{*}{ IV/silicalite } & 0.19 & 73.9 & 16.2 & 9.2 & 400 \\
\hline & 0.32 & 70.3 & 17.4 & 11.9 & 425 \\
\hline & 0.51 & 69.2 & 18.4 & 11.7 & 450 \\
\hline & 0.93 & 63.3 & 19.0 & 17.1 & 475 \\
\hline \multirow{3}{*}{ IV/ZSM-5 } & 1.15 & 46.8 & 37.1 & 15.9 & 400 \\
\hline & 1.90 & 48.6 & 39.7 & 11.5 & 425 \\
\hline & 3.30 & 46.7 & 40.5 & 12.5 & 450 \\
\hline \multirow[t]{3}{*}{ HZSM-5 } & 0.34 & 20.4 & 16.5 & 61.6 & 400 \\
\hline & 0.63 & 26.9 & 16.0 & 55.4 & 425 \\
\hline & 1.16 & 30.6 & 16.4 & 50.8 & 450 \\
\hline \multirow[t]{3}{*}{ IV/ZSM-5 $5^{d}$} & 0.81 & 57.5 & & & 400 \\
\hline & 1.27 & 59.4 & & & 425 \\
\hline & 2.14 & 55.4 & & & 450 \\
\hline
\end{tabular}

a $0.2 \mathrm{~g}$ of catalyst; total flow rate $=18 \mathrm{~mL} / \mathrm{min}$; air to ethane ratio $=2: 1 \mathrm{by}$ volume; total pressure $=1 \mathrm{~atm} .{ }^{b}$ Conversion of ethane. ${ }^{c}$ Reaction temperature. ${ }^{d}$ Data were from those over IV/ZSM-5 subtracted by those over HZSM-5.

Other than IV/ZSM-5, all the other vanadium-containing samples have desorption bands appearing at temperatures lower than $250^{\circ} \mathrm{C}$, which corresponds to physical and weakly chemical adsorption of ammonia. The amount of ammonia desorbed per unit surface area from HVAPO5-101 was nearly 2.5 times higher than that from IV/AlPO $4^{-}$ 5. This suggests that, upon calcination, some defects may be built in the structure of HVAPO-5-101 accompanying the formation of some additional acidic sites. Furthermore, HVAPO-5-101 and IV/AlPO 4 -5 have larger amounts of ammonia desorbed per surface area than IV/ZSM-5, IV/silica, and IV/silicalite. This is attributed to the higher polarity of $\mathrm{Al}-\mathrm{O}-\mathrm{P}$ bonding in the formal aluminophosphate surfaces than that of $\mathrm{Si}-\mathrm{O}-\mathrm{Si}$ or $\mathrm{Si}-\mathrm{O}-\mathrm{Al}$ bonding in the later surfaces.

Catalytic Measurements. When the supported vanadium oxides prepared in this research were used as catalysts for ethane oxydehydrogenation, ethylene was obtained as the major product and carbon oxides were the minor products. The results are listed in Table 3. Since methane, acetaldehyde, and higher hydrocarbons were detected only in very trace amount, they were not taken into account in the selectivity calculation. Furthermore, among the supports only HZSM-5 showed significant ethane conversion. The products consist of carbon monoxide and a slight amount of ethylene and carbon dioxide. Therefore, the reaction results over IV/ZSM-5 subtracted by those over HZSM-5 are also listed in Table 3.

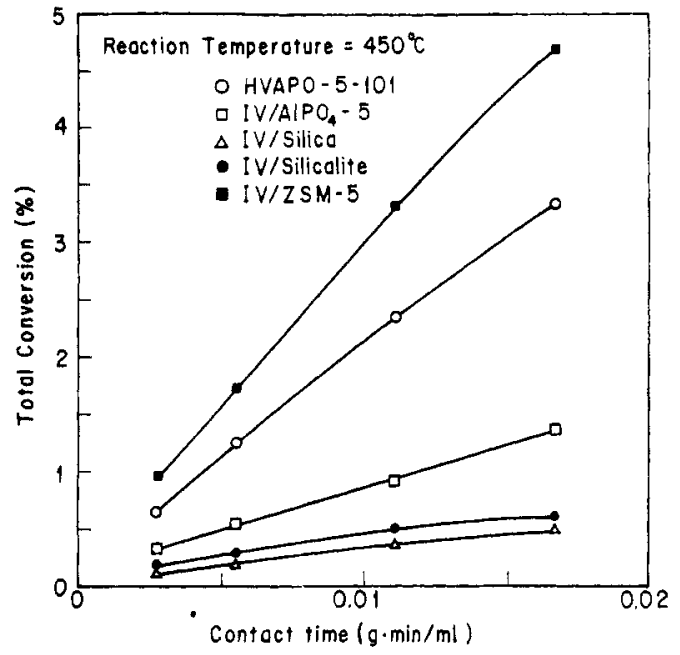

Figure 1. Total conversion of ethane oxidative dehydrogenation as a function of contact time at $450^{\circ} \mathrm{C}$ and 1 atm over HVAPO-5-101 and vanadium oxide impregnated on either $\mathrm{AlPO}_{4}-5$, silica gel, silicalite, or HZSM-5. Ethane to air ratio was 1:2 at the reactor inlet.

IV/ silica was found to have the least activity, due to the low dispersion of vanadium oxide on silica gel surface. It is also interesting to find that the reaction activity on IV/ZSM-5 was nearly 4 times higher than that on IV/ silicalite. Because the dispersion and the loading of vanadium oxide on HZSM-5 were less than those on silicalite, the number of vanadium active sites on silicalite for the reaction should be more than that on HZSM-5. Moreover, the binding energies of $\mathrm{V} 2 \mathrm{p}_{3 / 2}$ on both supports were the same. If each active site provides the same reaction activity on both supports, it is expected that the catalytic activity of IV/silicalite should have been greater than that of IV/ZSM-5. However, the reaction results shown in Table 3 are to the contrary. The significant difference between these two catalysts was the acidity of the supports. HZSM-5 has more and stronger acidic sites than silicalite. Thus, the inference which we can draw is that the acidic sites on the supports are capable to enhance ethane oxydehydrogenation activity over vanadium oxide. Nevertheless, this enhancement is only significant for reactions in the presence of oxygen. When air flow was substituted by the same flow rate of nitrogen in the ethane dehydrogenation reaction, and the rest of reaction conditions were maintained the same, approximately similar low ethane conversions, $0.3 \%$, were obtained from both IV/silicalite and IV/ZSM-5 catalyst systems at the reaction temperature of $450^{\circ} \mathrm{C}$.

For IV/AlPO 4 -5 and HVAPO-5-101, similar acidityenhancing-activity can also be used to explain the reaction results, as shown in Table 3 . Both catalysts have the values of vanadium oxide dispersion in a close range. Though IV/AlPO $\mathrm{A}_{4}-5$ had a slightly higher vanadium loading than HVAPO-5-101, the larger amount of acidic sites on HVAPO-5-101 makes the reaction activity nearly 2.5 times higher than that on IV/AlPO $4-5$.

Figure 1 shows the total conversion of ethane as a function of contact time for each catalyst at $450{ }^{\circ} \mathrm{C}$. Contact time was defined by the weight of catalyst divided by the total volumetric flow rate. Here, the data on IV/ ZSM-5 were not adjusted against the effect of HZSM-5 support. This shows that the activity decreases in the order of IV/ZSM-5 > HVAPO-5-101 > IV/AlPO $4-5>$ IV/ silicalite $>$ IV/silica. Again, those catalysts with fewer acidic sites have lower activities. Figures 2-4 display the variations of product selectivities versus ethane conversion. On one hand, it was found that other than IV/ZSM-5 the selectivities of ethylene could be extrapolated to approach 


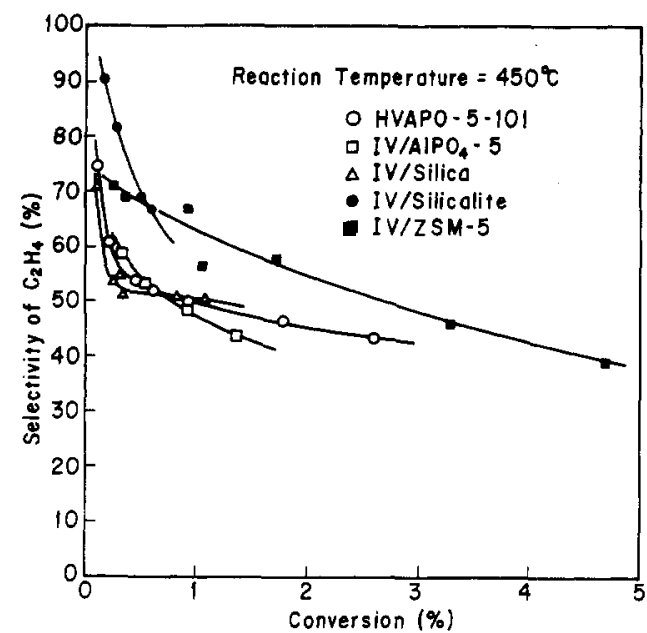

Figure 2. Ethylene selectivity as a function of ethane conversion at $450^{\circ} \mathrm{C}$ and 1 atm over HVAPO-5-101 and vanadium oxide impregnated on either $\mathrm{AlPO}_{4}-5$, silica gel, silicalite, or HZSM-5. Ethane to air ratio was 1:2 at the reactor inlet.

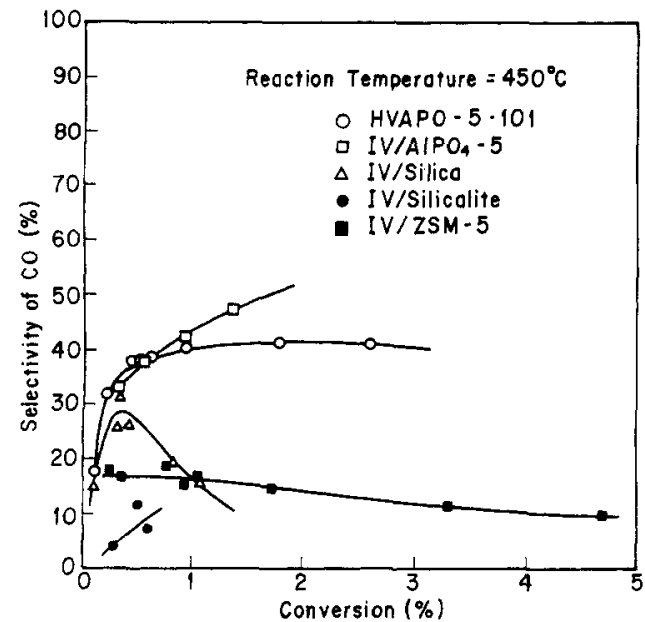

Figure 3. Carbon monoxide selectivity as a function of ethane conversion at $450^{\circ} \mathrm{C}$ and 1 atm over HVAPO-5-101 and vanadium oxide impregnated on either $\mathrm{AlPO}_{4}-5$, silica gel, silicalite, or HZSM5. Ethane to air ratio was $1: 2$ at the reactor inlet.

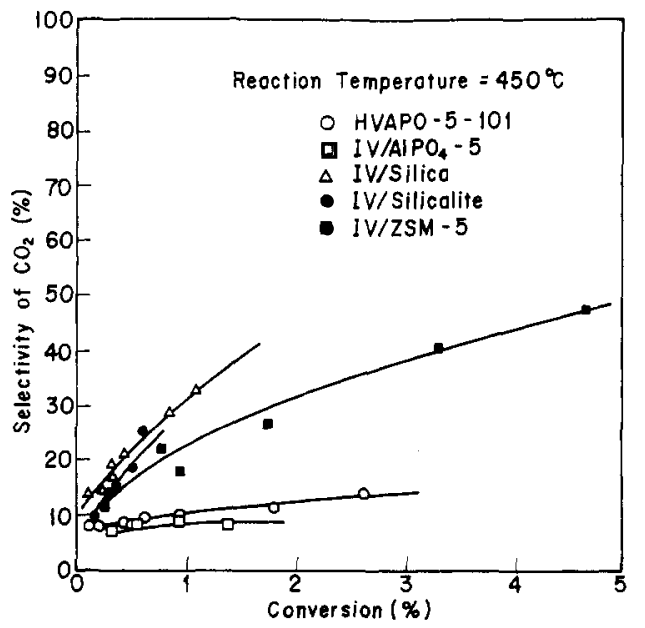

Figure 4. Carbon dioxide selectivity as a function of ethane conversion at $450^{\circ} \mathrm{C}$ and 1 atm over HVAPO-5-101 and vanadium oxide impregnated on either $\mathrm{AlPO}_{4}-5$, silica gel, silicalite, or HZSM5. Ethane to air ratio was $1: 2$ at the reactor inlet.

$100 \%$ when the total conversion was close to zero. That suggests that ethylene is the primary product, and carbon monoxide and carbon dioxide are the products from ethylene. On the other hand, over IV/ZSM-5, the selectivities of ethylene and carbon monoxide approach $80 \%$ and $20 \%$, respectively, when ethane conversion is ex-

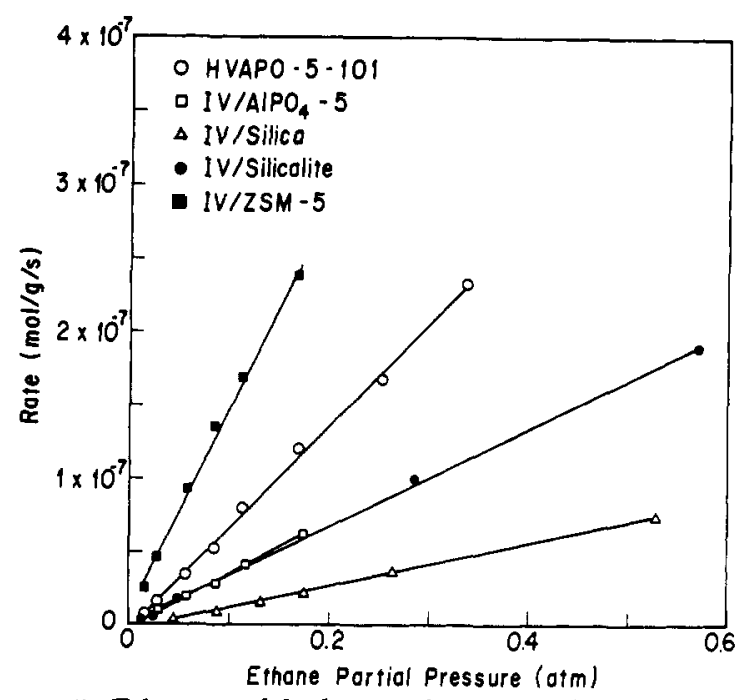

Figure 5. Ethane oxydehydrogenation rate against ethane partial pressure at constant oxygen partial pressure, $450^{\circ} \mathrm{C}$, and 1 atm total pressure. Fixed oxygen partial pressure: HVAPO-5-101, 0.0208 atm: IV/AlPO 4 -5, $0.0214 \mathrm{~atm} ; \mathrm{IV} /$ silica, $0.0326 \mathrm{~atm}$ IV/silicalite, 0.0352 atm; IV/ZSM-5, $0.0207 \mathrm{~atm}$.

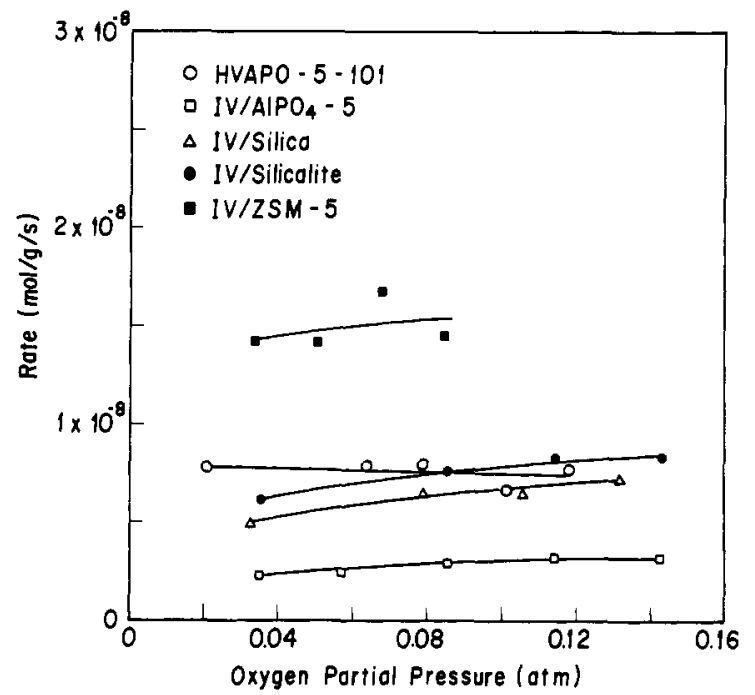

Figure 6. Ethane oxydehydrogenation rate against oxygen partial pressure at constant ethane partial pressure $450^{\circ} \mathrm{C}$, and 1 atm total pressure. Fixed ethane partial pressure: HVAPO-5-101, 0.0141 atm; IV/AIPO $-5,0.0119 \mathrm{~atm} ;$ IV/silica, $0.0441 \mathrm{~atm}$ IV/silicalite, 0.0238 atm; IV/ZSM-5, 0.00712 atm.

trapolated to zero. Therefore, ethylene and carbon monoxide were formed in parallel over IV/ZSM-5. This is attributed to HZSM-5 itself being a catalyst for carbon monoxide formation.

Figures 3 and 4 depict that the selectivities of carbon monoxide increased with the ethane conversion and then some of them leveled off and slightly decreased with further increase of ethane conversion. The selectivities of carbon dioxide always increased with the ethane conversion. Thus the reaction sequence after the production of ethylene on these supported vanadium oxides can be regarded as that carbon monoxide is from the oxidation of ethylene, and is oxidized to carbon dioxide subsequently.

Reaction Kinetics. The rate of ethane oxydehydrogenation at $450^{\circ} \mathrm{C}$ over each supported vanadium catalyst is plotted against the partial pressure of ethane in Figure 5 and oxygen in Figure 6; the detailed data are listed in Table 4. It was observed that all the rates had a linear relationship with ethane partial pressure, suggesting that the reaction rate was first order in the ethane concentration on each catalyst. On the other hand, the plot of reaction rates versus oxygen partial pressure in Figure 6, although 
2070 Ind. Eng. Chem. Res., Vol. 33, No. 9, 1994

Table 4. Kinetic Data Used in Modeling

\begin{tabular}{|c|c|c|c|c|c|c|}
\hline catalyst & $P_{\mathrm{C}_{2} \mathrm{H}_{8}}$, atm & $P_{\mathrm{O}_{2}}$, atm & rate, $\mathrm{mol} /(\mathrm{g} \cdot \mathrm{s})$ & $P_{\mathrm{C}_{2} \mathrm{H}_{0}}$, atm & $P_{\mathrm{O}_{2}}$, atm & rate, $\mathrm{mol} /(\mathrm{g} \cdot \mathrm{s})$ \\
\hline \multirow[t]{7}{*}{ IV/silica } & 0.0441 & 0.0326 & $5.04 \mathrm{E}-09$ & 0.264 & 0.0793 & $4.58 \mathrm{E}-08$ \\
\hline & 0.0881 & 0.0326 & $1.02 \mathrm{E}-08$ & 0.264 & 0.106 & $4.99 \mathrm{E}-08$ \\
\hline & 0.132 & 0.0326 & $1.68 \mathrm{E}-08$ & 0.264 & 0.132 & $5.64 \mathrm{E}-08$ \\
\hline & 0.176 & 0.0326 & $2.28 \mathrm{E}-08$ & 0.0441 & 0.132 & $7.34 \mathrm{E}-09$ \\
\hline & 0.264 & 0.0326 & $3.79 \mathrm{E}-08$ & 0.0441 & 0.106 & $6.57 \mathrm{E}-09$ \\
\hline & 0.529 & 0.0326 & $7.63 \mathrm{E}-08$ & 0.0441 & 0.0793 & $6.56 \mathrm{E}-09$ \\
\hline & 0.264 & 0.0793 & $4.78 \mathrm{E}-08$ & & & \\
\hline \multirow[t]{15}{*}{ IV/ZSM-5 } & 0.00677 & 0.0200 & $1.26 \mathrm{E}-08$ & 0.0141 & 0.0207 & $2.58 \mathrm{E}-08$ \\
\hline & 0.0135 & 0.0200 & $2.35 \mathrm{E}-08$ & 0.0283 & 0.0207 & $4.62 \mathrm{E}-08$ \\
\hline & 0.0269 & 0.0200 & $4.40 \mathrm{E}-08$ & 0.0567 & 0.0207 & $9.40 \mathrm{E}-08$ \\
\hline & 0.0536 & 0.0200 & $8.80 \mathrm{E}-08$ & 0.0851 & 0.0207 & $1.36 \mathrm{E}-07$ \\
\hline & 0.0812 & 0.0200 & $1.32 \mathrm{E}-07$ & 0.113 & 0.0207 & $1.69 \mathrm{E}-07$ \\
\hline & 0.108 & 0.0200 & $1.78 \mathrm{E}-07$ & 0.170 & 0.0207 & $2.38 \mathrm{E}-07$ \\
\hline & 0.162 & 0.0200 & $2.90 \mathrm{E}-07$ & 0.00712 & 0.0340 & $1.42 \mathrm{E}-08$ \\
\hline & 0.00677 & 0.0325 & $1.31 \mathrm{E}-08$ & 0.00712 & 0.0510 & $1.42 \mathrm{E}-08$ \\
\hline & 0.00677 & 0.0487 & $1.46 \mathrm{E}-08$ & 0.00712 & 0.0681 & $1.68 \mathrm{E}-08$ \\
\hline & 0.00677 & 0.0650 & $1.50 \mathrm{E}-08$ & 0.00712 & 0.0851 & $1.45 E-08$ \\
\hline & 0.00677 & 0.0812 & $1.44 \mathrm{E}-08$ & 0.340 & 0.0851 & $6.69 \mathrm{E}-07$ \\
\hline & 0.325 & 0.0812 & $7.21 \mathrm{E}-07$ & 0.340 & 0.0681 & $6.59 \mathrm{E}-07$ \\
\hline & 0.325 & 0.0650 & $6.56 \mathrm{E}-07$ & 0.340 & 0.0510 & $5.48 \mathrm{E}-07$ \\
\hline & 0.325 & 0.0325 & $5.13 \mathrm{E}-07$ & 0.340 & 0.0340 & $5.16 \mathrm{E}-07$ \\
\hline & 0.325 & 0.0200 & $4.65 \mathrm{E}-07$ & 0.340 & 0.0207 & $4.44 \mathrm{E}-07$ \\
\hline \multirow[t]{8}{*}{ IV/silicalite } & 0.0119 & 0.0352 & $5.20 \mathrm{E}-09$ & 0.286 & 0.0572 & $1.04 \mathrm{E}-07$ \\
\hline & 0.0238 & 0.0352 & $9.09 \mathrm{E}-09$ & 0.286 & 0.0857 & $1.14 \mathrm{E}-07$ \\
\hline & 0.0476 & 0.0352 & $1.76 \mathrm{E}-08$ & 0.286 & 0.114 & $1.19 \mathrm{E}-07$ \\
\hline & 0.0953 & 0.0352 & $4.30 \mathrm{E}-08$ & 0.286 & 0.143 & $1.27 \mathrm{E}-07$ \\
\hline & 0.143 & 0.0352 & $6.08 \mathrm{E}-08$ & 0.0238 & 0.0352 & $6.16 \mathrm{E}-09$ \\
\hline & 0.191 & 0.0352 & $7.57 \mathrm{E}-08$ & 0.0238 & 0.143 & $8.36 \mathrm{E}-09$ \\
\hline & 0.286 & 0.0352 & $1.00 \mathrm{E}-07$ & 0.0238 & 0.114 & $8.26 \mathrm{E}-09$ \\
\hline & 0.572 & 0.0352 & $1.89 \mathrm{E}-07$ & 0.0238 & 0.0857 & $7.61 \mathrm{E}-09$ \\
\hline \multirow{11}{*}{ IV/AlPO $4-5$} & 0.0119 & 0.0352 & $2.31 \mathrm{E}-09$ & 0.286 & 0.0857 & $1.64 \mathrm{E}-07$ \\
\hline & 0.0119 & 0.0571 & $2.48 \mathrm{E}-09$ & 0.286 & 0.0571 & $1.46 \mathrm{E}-07$ \\
\hline & 0.0119 & 0.0857 & $2.95 \mathrm{E}-09$ & 0.286 & 0.0352 & $1.20 \mathrm{E}-07$ \\
\hline & 0.0119 & 0.114 & $3.21 \mathrm{E}-09$ & 0.0145 & 0.0214 & $3.03 \mathrm{E}-09$ \\
\hline & 0.0119 & 0.143 & $3.17 \mathrm{E}-09$ & 0.0290 & 0.0214 & $9.07 \mathrm{E}-09$ \\
\hline & 0.0238 & 0.143 & $9.38 \mathrm{E}-09$ & 0.0579 & 0.0214 & $1.92 \mathrm{E}-08$ \\
\hline & 0.0476 & 0.143 & $2.47 \mathrm{E}-08$ & 0.0869 & 0.0214 & $2.84 \mathrm{E}-08$ \\
\hline & 0.0952 & 0.143 & $5.83 \mathrm{E}-08$ & 0.116 & 0.0214 & $4.13 \mathrm{E}-08$ \\
\hline & 0.143 & 0.143 & $9.34 \mathrm{E}-08$ & 0.174 & 0.0214 & $6.21 \mathrm{E}-08$ \\
\hline & 0.190 & 0.143 & $1.20 \mathrm{E}-07$ & 0.290 & 0.0579 & $1.53 \mathrm{E}-07$ \\
\hline & 0.286 & 0.114 & $1.81 \mathrm{E}-07$ & 0.290 & 0.116 & $1.86 \bar{E}-07$ \\
\hline \multirow[t]{9}{*}{ HVAPO-5-101 } & 0.0141 & 0.0208 & $7.81 \mathrm{E}-09$ & 0.0141 & 0.0383 & $1.04 \mathrm{E}-08$ \\
\hline & 0.0282 & 0.0208 & $1.56 \mathrm{E}-08$ & 0.0141 & 0.0641 & $7.86 \mathrm{E}-09$ \\
\hline & 0.0558 & 0.0208 & $3.43 \mathrm{E}-08$ & 0.0141 & 0.0789 & $7.93 \mathrm{E}-09$ \\
\hline & 0.0845 & 0.0208 & $5.21 \mathrm{E}-08$ & 0.0141 & 0.101 & $1.16 \mathrm{E}-08$ \\
\hline & 0.113 & 0.0208 & $8.06 \mathrm{E}-08$ & 0.0141 & 0.101 & $6.66 \mathrm{E}-09$ \\
\hline & 0.113 & 0.0208 & $7.98 \mathrm{E}-08$ & 0.0141 & 0.118 & $7.68 \mathrm{E}-09$ \\
\hline & 0.169 & 0.0208 & $1.20 \mathrm{E}-07$ & 0.338 & 0.0676 & $2.83 \mathrm{E}-07$ \\
\hline & 0.254 & 0.0208 & $1.67 \mathrm{E}-07$ & 0.338 & 0.0507 & $2.65 \mathrm{E}-07$ \\
\hline & 0.0338 & 0.0208 & $2.32 \mathrm{E}-07$ & 0.338 & 0.0338 & $2.50 \mathrm{E}-07$ \\
\hline
\end{tabular}

a little bit scattered, shows the order of oxygen being close to zero. These results echo well those over vanadium pentoxide supported on silica reported by Le Bars et al. (1992a). Noticeably, the present studies demonstrate that the reaction orders on various supports are in a close range. This suggests that the reaction kinetics on these supported vanadium oxides may be the same.

Several kinetic models and rate equations were developed to fit the data in Table 4 statistically. A SAS package was applied to do the regression. The parameters in each proposed rate equation were first estimated from linear regression (GLM program of SAS); then by using these estimated parameters as initial guesses, the improved parameters with $95 \%$ confidence intervals were obtained from nonlinear regression (Marqudart method in NLIN program of SAS). When any of the resultant estimated parameters was negative, that proposed rate equation was eliminated from further consideration. Thus, through the process mentioned above, more than 50 equations from 9 different reaction mechanisms, such as a LangmuirHinshelwood type with molecular or atomic adsorption on single or dual sites, a Rideal type for adsorption, or several reduction-oxidation mechanisms including that used by Le Bars et al. (1992a), have been examined.
Only the following equation could fit all the kinetics data from each catalyst satisfactorily:

$$
\text { rate }=\frac{k P_{\mathrm{C}_{2} \mathrm{H}_{8}} P_{\mathrm{O}_{2}}{ }^{1 / 2}}{\left(1+K_{0} P_{\mathrm{O}_{2}}{ }^{1 / 2}\right)^{2}}
$$

where $P_{\mathrm{C}_{2} \mathrm{H}_{6}}$ and $P_{\mathrm{O}_{2}}$ represent partial pressures of ethane and oxygen, respectively. $k$ and $K_{O}$ are constants. Figure 7 shows that the rate data from experiments are in good agreement with those estimated from eq 1 . It also shows that the data from IV/ZSM-5 has the poorest fitting among the catalysts studied, probably due to the support effect on reaction. Nevertheless, the random distribution around the diagonal line of empirical and calculated rate values suggests that this rate equation describes all the experimental results quite well.

Under the assumptions of small adsorption equilibrium constant of ethane and low product concentrations, eq 1 was derived from a Langmuir-Hinshelwood mechanism with single type active sites on the catalyst surface, as well as the surface reaction being the rate-determining step and oxygen being dissociatively adsorbed. However, from the experimental evidence obtained by Le Bars et al. (1992b) and Oyama et al. (1989), vanadium pentoxide 


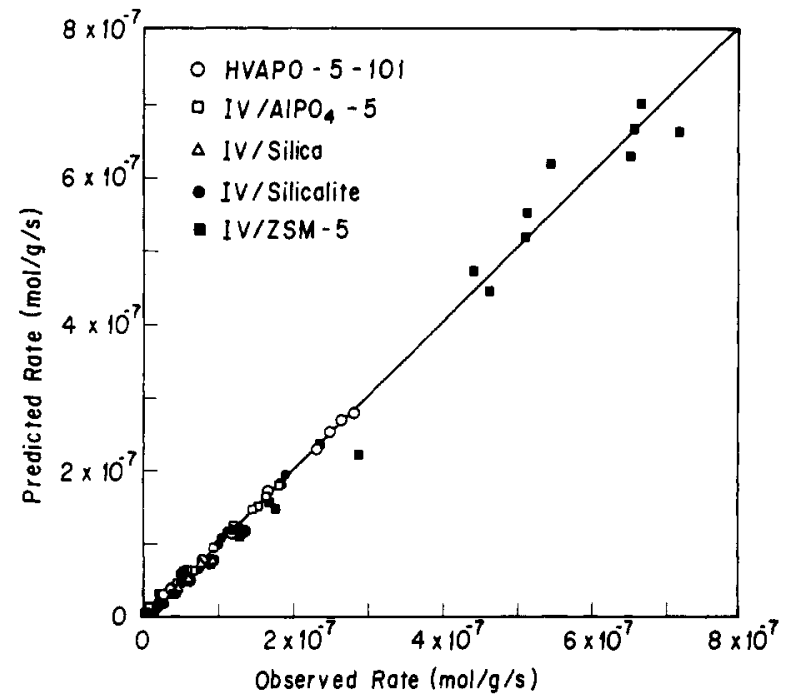

Figure 7. Comparison of predicted and observed values of ethane oxydehydrogenation rates over HVAPO-5-101, IV/AlPO ${ }_{4}-5, \mathrm{IV} /$ silica, IV/silicalite, and IV/ZSM-5.

is easily reduced by ethane, ethylene, or hydrogen and reoxidized by oxygen. Therefore, the following mechanism involving vanadium oxide reduction-oxidation in combination with ethane adsorption and the desorption of ethylene and water was considered:

$$
\begin{gathered}
\mathrm{C}_{2} \mathrm{H}_{6}+\mathrm{VO} \rightleftarrows \mathrm{C}_{2} \mathrm{H}_{6} \cdot \mathrm{VO} \\
\mathrm{C}_{2} \mathrm{H}_{6} \cdot \mathrm{VO}+\mathrm{V} \rightarrow \mathrm{C}_{2} \mathrm{H}_{4} \cdot \mathrm{V}+\mathrm{H}_{2} \mathrm{O} \cdot \mathrm{V} \\
\mathrm{C}_{2} \mathrm{H}_{4} \cdot \mathrm{V} \rightleftharpoons \mathrm{C}_{2} \mathrm{H}_{4}+\mathrm{V} \\
\mathrm{H}_{2} \mathrm{O} \cdot \mathrm{V} \rightleftarrows \mathrm{H}_{2} \mathrm{O}+\mathrm{V} \\
\mathrm{V}+{ }^{1 / 2} \mathrm{O}_{2} \rightleftarrows \mathrm{VO}
\end{gathered}
$$

where $V O$ and $V$ represent vanadium oxide and its reduced form, respectively. Assuming that reaction 3 is the ratedetermining step, and the equilibrium constant of reaction 2 is relatively small while those of reactions 4 and 5 are relatively large, the rate law can be derived in a form similar to that of eq 1:

$$
\text { rate }=\frac{k_{3} K_{2} K_{6} C_{t}{ }^{2} P_{\mathrm{C}_{2} \mathrm{H}_{6}} P_{\mathrm{O}_{2}}{ }^{1 / 2}}{\left(1+K_{6} P_{\mathrm{O}_{2}}{ }^{1 / 2}\right)^{2}}
$$

where $k_{3}$ is the rate constant of reaction $3, K_{2}$ is the adsorption equilibrium constant of ethane on vanadium oxide in eq $2, K_{6}$ is the oxidation equilibrium constant of reduced vanadium oxide in eq 6 , and $C_{\mathrm{t}}$ is the total number of active sites on vanadium oxide. The mechanism describes that ethane in the gas phase first adsorbs on the surface of vanadium oxide and then this adsorbed species reduces vanadium oxide to produce ethylene and water, which are temporarily adsorbed on the surface of reduced vanadium oxide. These two products then quickly desorb from the reduced surface, and the reduced vanadium oxide is subsequently oxidized back to vanadium oxide. It is noticeable that Le Bars et al. (1992a) reported a similar oxidation-reduction rate-limiting step for ethane oxydehydrogenation over vanadium pentoxide supported on silica. However, they did not consider any adsorption steps, and their formulated rate equation could not fit some of our experimental data well by regression processes

\begin{tabular}{|c|c|c|c|}
\hline catalyst & $\begin{array}{c}k_{3} K_{2} K_{8} C_{t}{ }^{2} \\
10^{-6} \mathrm{~mol} /\left(\mathrm{atm}^{3 / 2} \cdot \mathrm{g} \cdot \mathrm{s}\right)\end{array}$ & $\begin{array}{c}K_{6} \\
1 / \text { atm }^{1 / 2}\end{array}$ & $\begin{array}{r}\mathrm{rel}^{a} \\
k_{3} K_{2}\end{array}$ \\
\hline $\begin{array}{l}\text { IV/ZSM-5 } \\
\text { IV/silicalite } \\
\text { IV/silica } \\
\text { IV/AIPO } \\
\text { HVAPO-5-101 }\end{array}$ & $\begin{array}{r}13.8 \pm 2.2 \\
3.37 \pm 0.66 \\
1.15 \pm 0.17 \\
3.19 \pm 0.33 \\
8.82 \pm 0.87\end{array}$ & $\begin{array}{l}1.37 \pm 0.46 \\
1.91 \pm 0.58 \\
1.21 \pm 0.36 \\
0.931 \pm 0.221 \\
2.57 \pm 0.38\end{array}$ & $\begin{array}{l}4.61 \\
0.33 \\
1.0 \\
2.23 \\
6.98\end{array}$ \\
\hline
\end{tabular}
previously illustrated.

Table 5 lists the estimated values of apparent rate constant, $k_{3} K_{2} K_{6} C_{t}^{2}$, oxidation equilibrium constant, $K_{6}$,
Table 5. Estimated Values of Parameters and $95 \%$ Confidence Intervals

and the relative $k_{3} K_{2}$ value of each catalyst to that of IV/ silica, as well as some of the standard errors and $95 \%$ confidence intervals of these estimated values. The results show that the oxidation equilibrium constants $\left(K_{6}\right)$ of the catalyst prepared by impregnation were all in a close range; their $95 \%$ confidence intervals significantly overlap one another. This implies that vanadium oxide of similar form and property probably existed on the surface of each impregnation sample. The variations in support acidity (i.e., HZSM-5 and $\mathrm{AlPO}_{4}-5$ ) and support strutures (i.e., the different structures of silicalite, $\mathrm{AlPO}_{4}-5$, and amorphous silica) provided only little influence on oxidation equilibria of the catalysts. It is noteworthy that the $K_{6}$ value of HVAPO-5-101 (Table 5) is higher than those of the impregnation samples. Moreover, the difference is even more pronounced when HVAPO-5-101 and IV/AlPO ${ }_{4}^{-}$ 5 , both of the same aluminophosphate supports, were compared. We think this is attributed to the hydrothermal method used for the preparation of the former catalyst, in which vanadium might be bonded or isomorphously substituted in the aluminophosphate. The higher value of $K_{6}$ over HVAPO-5-101 suggests that the reduced vanadium oxide is more easily oxidized back. A similar character has also been reported by Iton et al. (1989) for cobalt-substituted aluminophosphate prepared by hydrothermal method.

The relative $k_{3} K_{2}$ value listed in Table 5 is the product of the intrinsic surface reaction rate constant $\left(k_{3}\right)$ and the ethane adsorption equilibrium constant $\left(K_{2}\right)$ relative to that of IV/silica. The values depict the support effect on reactions 2 and 3 , and the value of 1 represents that these reactions have the same influence from the support as that from silica support.

It was found that the $k_{3} K_{2}$ value for IV/silicalite was smaller than that for IV/silica, or the relative $k_{3} K_{2}$ value of IV/silicalite was less than 1 . Considering that both silicalite and silica are composed of silicon oxide, the adsorption equilibrium constants of ethane on the vanadium oxide supported on them should not be different significantly. Indeed, our reaction kinetics study reveals that the equilibrium constants $\left(K_{6}\right)$ for IV/silica and IV/ silicalite are in a close range, but the intrinsic rate constant $\left(k_{3}\right)$ for IV/silica is significantly larger than that for IV/ silicalite. Therefore, the turnover number of ethane oxydehydrogenation over IV/silica should be greater than that over IV/silicalite. In other words, the low catalytic activity of IV/silica (based on catalyst weight) for ethane oxydehydrogenation was not attributed to the low reaction rate over vanadium oxide site on silica support. Indeed, it is due to the poorest vanadium dispersion on silica, which caused the small value of $C_{\mathrm{t}}{ }^{2}$ in the rate equation.

The relative $k_{3} K_{2}$ values in Table 5 also demonstrate that these values have strong correlation with the acidity of the supports (listed in Table 2). The values for IV/ ZSM-5, IV/AlPO 4 -5, and HVAPO-5-101 are larger than 1, indicating that both acidic strength (i.e., on HZSM-5) and the number of acidity sites per surface area (i.e., HVAPO5-101 and $\left.\mathrm{AlPO}_{4}-5\right)$ could enhance the $k_{3} K_{2}$ values. Furthermore, the acidity effect on $k_{3} K_{2}$ values can be even 
pronounced if we exclude the possible support structure effects. Therefore, if the relative $k_{3} K_{2}$ values of IV/ZSM-5 and IV/silicalite (both supports possessing the same pentasil structure) are compared, the more and stronger acidic sites on IV/ZSM-5 cause a more than 10-fold increase in either the reaction rate of the limiting step or the ethane adsorption equilibrium constant. Similarly, the more acidic sites on HVAPO-5-101 caused the $k_{3} K_{2}$ value more than 3 times larger than that for IV/AlPO ${ }_{4}-5$, although both possess the same $\mathrm{AlPO}_{4}-5$ structure.

\section{Conclusion}

The present studies of ethane oxydehydrogenation reveal that the acidic sites of the supports can enhance the catalytic activity of vanadium oxide supported on them. Therefore, vanadium oxide impregnated on HZSM-5 has a much higher reaction activity than that on silicalite. Moreover, the same reason accounted for the higher ethane conversion over vanadium aluminophosphate, HVAPO5-101 (prepared by hydrothermal method), than that over vanadium oxide impregnated on $\mathrm{AlPO}_{4}-5$, both having the same crystal structure as $\mathrm{AlPO}_{4}-5$.

Under the reaction conditions used in this study, the rates of ethane oxydehydrogenation over vanadium oxide supported on various supports, silica, HZSM-5, silicalite, and $\mathrm{AlPO}_{4}-5$, can be expressed as

$$
\text { rate }=\frac{k_{3} K_{2} K_{6} C_{t}{ }^{2} P_{\mathrm{C}_{2} \mathrm{H}_{6}} P_{\mathrm{O}_{2}}{ }^{1 / 2}}{\left(1+K_{6} P_{\mathrm{O}_{2}}{ }^{1 / 2}\right)^{2}}
$$

From the proposed reaction mechanism, it seems that ethane is adsorbed on vanadium oxides first and then through the reduction of vanadium oxide sites (ratedetermining step) ethylene and water are formed. Finally, the reduced vanadium oxide is oxidized back to vanadium oxide by oxygen. The estimated parameters from this rate equation provided the evidence that acidic sites of the supports could either enhance the surface reaction rate constant or increase the ethane adsorption equilibrium constant on the catalysts.

\section{Acknowledgment}

The financial support from the National Science Council in Taiwan, ROC, under Contract No. 80-0402-E002-12, is appreciated.

\section{Nomenclature}

$C_{\mathrm{t}}=$ total number of active sites on vanadium oxide (mol of $\mathrm{V} / \mathrm{g}$ )

$k=$ rate constant $\left(\mathrm{mol} /\left(\mathrm{atm}^{3 / 2} \cdot \mathrm{g} \cdot \mathrm{s}\right)\right)$

$k_{3}=$ rate constant of surface reaction $\left(\mathrm{mol} \cdot \mathrm{g} /\left((\mathrm{mol} \text { of V})^{2} \cdot \mathrm{s}\right)\right)$

$K_{2}=$ ethane adsorption equilibrium constant (1/atm)

$K_{6}$ and $K_{0}=$ oxidation equilibrium constant of vanadium oxide $\left(1 /\right.$ atm $\left.^{1 / 2}\right)$

$P_{\mathrm{C}_{2} \mathrm{H}_{6}}=$ partial pressure of ethane (atm)

$P_{\mathrm{O}_{2}}=$ partial pressure of oxygen (atm)

Compounds

$\mathrm{Al}_{2} \mathrm{O}_{3}=$ alumina

$\mathrm{Et}_{3} \mathrm{~N}=$ triethylamine

$\mathrm{H}_{2} \mathrm{O}=$ water

$\mathrm{H}_{3} \mathrm{PO}_{4}=$ phosphoric acid

$\mathrm{V}=$ vanadium

$\mathrm{V}_{2} \mathrm{O}_{5}=$ vanadium pentoxide

\section{Literature Cited}

Burch, R.; Swarnakar, R. Oxidative Dehydrogenation of Ethane on Vanadium-Molybdenum Oxide and Vanadium-Niobium-Molybdenum Oxide Catalysts. Appl. Catal. 1991, 70, 129.

Cotton, F. A.; Wilkinson, G. In Advanced Inorganic Chemistry, A Comprehensive Text, 3rd ed.; John Wiley \& Sons, Inc.: New York, NY, 1972

Erdöhelyi, A.; Solymosi, F. Partial Oxidation of Ethane over $\mathrm{KVO}_{3} /$ $\mathrm{SiO}_{2}$ and Potassium Promoted $\mathrm{V}_{2} \mathrm{O}_{5} / \mathrm{SiO}_{2}$ Catalysts. J. Catal. 1988, $39, \mathrm{~L} 11$.

Erdöhelyi, A.; Solymosi, F. Partial Oxidation of Ethane over Supported Vanadium Pentoxide Catalysts. J. Catal. 1990, 123, 31.

Erdöhelyi, A.; Solymosi, F. Oxidation of Ethane over Silica-Supported Alkali Matal Vanadate Catalysts. J. Catal. 1991, 129, 497.

Fierro, J. L. G.; Gambaro, L. A.; Cooper, T. A.; Kremenic, G. Structure and Activity of Silica-Supported Vanadia Catalysts for the Oxidation of Propylene. Appl. Catal. 1983, 6, 363.

Fujimoto, K.; Nakamura, I.; Yokota, K. Oxidative Dehydrogenation of Lower Paraffins with ZSM-5 Zeolite Catalysts. Zeolites 1989, 9,120 .

Gil-Llambi'as, F. J.; Escudey, A. M.; Fierro, J. L. G.; Agudo, A. L. Determination of the Active Surface Aera of Vanadia by Electrophoretic Migration and XPS Measurements. J. Catal. 1985, 95,520 .

Iton, L. E.; Choi, I.; Desjardins, J. A.; Maroni, V. A. Stabilization of $\mathrm{Co}$ (III) in Aluminophosphate Molecular Sieve Frameworks. Zeolites 1989, 9, 535.

Le Bars, J.; Vedrine, J. C.; Auroux, A.; Trautmann, S.; Baerns, M. Role of Surface Acidity on Vanadia/Silica Catalysts Used in the Oxidative Dehydrogenation of Ethane. Appl. Catal. 1992a, 88, 179.

Le Bars, J.; Vedrine, J. C.; Auroux, A.; Pommier, B.; Pajonk, G. M. Calorimetric Study of Vanadium Pentoxide Catalysts Used in the Reaction of Ethane Oxidative Dehydrogenation. J. Phys. Chem. 1992b, 96, 2217.

Lok, B. M.; Marcus, B. K.; Angell, C. L. Characterization of Zeolite Acidity. II. Measurement of Zeolite Acidity by Ammonia Temperature Programmed Desorption and FT i.r. Spectroscopy Techniques. Zeolites 1986, 6, 185.

Nag, N. K.; Massoth, F. E. ESCA and Gravimetric Reduction Studies on $\mathrm{V} / \mathrm{Al}_{2} \mathrm{O}_{3}$ and $\mathrm{V} / \mathrm{SiO}_{2}$ Catalysts. J. Catal. 1990, 124, 127.

Oyama, S. T. Adsorbate Bonding and the Selection of Partial and Total Oxidation Pathways. J. Catal. 1991, 128, 210.

Oyama, S. T.; Somorjai, G. A. Effect of Structure in Selective Oxide Catalysis. J. Phys. Chem. 1990, 94, 5022.

Oyama, S. T.; Went, G. T.; Lewis, K. B.; Bell, A. T.; Somorjai, G. A. Oxygen Chemisorption and Laser Raman Spectroscopy of Unsupported and Silica-Supported Vanadium Oxide Catalysts. J. Phys. Chem. 1989, 93, 6786 .

Oyama, S. T.; Middlebrook, A. M.; Somorjai, G. A. Kinetics of Ethane Oxidation on Vanadium Oxide. J. Phys. Chem. 1990, 94, 5029.

Rigutto, M. S.; van Bekkum, H. Vanadium Site in VAPO-5: Characterization and Catalytic Properties in Liquid-Phase Alkene Epoxidation and Benzylic Oxidation. J. Mol. Catal. 1993, 81, 77.

Thorsteinson, E. M.; Wilson, T. P.; Young, F. G.; Kasai, P. H. The Oxidative Dehydrogenation of Ethane over Catalysts Containing Mixed Oxides of Molybdenum and Vanadium. J. Catal. 1978, 52, 116.

Wan, B.-Z.; Yang, T. C. Preparation and Catalytic Properties of Transition Metal Doped ZSM-5. J. Chin. Chem. Soc. 1990, 37, 255.

Wan, B.-Z; Huang, K. MnAPO-5 as A Catalyst for Ethane Orydehydrogenation. Appl. Catal. 1991, 73, 113.

Wan, B.-Z.; Huang, K.; Yang, T. C.; Tai, C.-Y. Characterization and Catalytic Properties of MAPO-5. J. Chin. Inst. Chem. Eng. 1991, $22,17$.

Received for review December 21, 1993 Revised manuscript received June 2, 1994 Accepted June 13, 1994*

\footnotetext{
Abstract published in Advance ACS Abstracts, July 15, 1994.
} 